\title{
Percutaneous Coronary Intervention in Spontaneous Coronary Artery Dissection: Role of Intravascular Ultrasound
}

\author{
Ankur Kalra $\cdot$ Avin Aggarwal $\cdot$ Rachel Kneeland $\cdot$ Jay H. Traverse
}

To view enhanced content go to www.cardiologytherapy-open.com

Received: June 12, 2014 / Published online: August 20, 2014

(C) The Author(s) 2014. This article is published with open access at Springerlink.com

\section{ABSTRACT}

Spontaneous coronary artery dissection (SCAD) is a rare, life-threatening condition that usually manifests as an acute myocardial infarction. Diagnosing SCAD with conventional coronary angiogram can be challenging, particularly if the true lumen is severely narrowed. Our case highlights the challenges in performing successful percutaneous coronary intervention (PCI) in patients with SCAD. Intravascular ultrasound can prove to be a pivotal tool in

Electronic supplementary material The online version of this article (doi:10.1007/s40119-014-0029-4) contains supplementary material, which is available to authorized users.

A. Kalra $(\bowtie) \cdot$ J. H. Traverse

Minneapolis Heart Institute at Abbott Northwestern

Hospital, Minneapolis, MN, USA

e-mail: ankur.kalra@hcmed.org;

kalramd.ankur@gmail.com

A. Aggarwal

Department of Medicine, Hennepin County

Medical Center, Minneapolis, MN, USA

R. Kneeland

Arizona College of Osteopathic Medicine,

Midwestern University, Glendale, AZ, USA

J. H. Traverse

Department of Cardiology, University of Minnesota

Medical School, Minneapolis, MN, USA the diagnosis and successful management of such cases by establishing the anatomic site of dissection, and confirming stent placement in the true lumen following PCI.

Keywords: Cardiology; False lumen; Intravascular ultrasound; Percutaneous coronary intervention; Postpartum dissection; Spontaneous coronary artery dissection

\section{INTRODUCTION}

Spontaneous coronary artery dissection (SCAD) is a life-threatening disorder that usually affects young women. A high index of suspicion is necessary for diagnosing SCAD, as the classic longitudinal radiolucent intimal flap may not be seen in every patient on angiography. Additional tomographic imaging techniques like intravascular ultrasound (IVUS), therefore, play a crucial role in establishing the right diagnosis. In addition, IVUS is also important in ensuring appropriate positioning of wires and catheters in the true lumen during intervention, and satisfactory stent deployment. Here, we present a case that highlights the challenges in 
performing successful percutaneous coronary intervention (PCI) in patients with SCAD. Informed consent was obtained from the patient for publication of this case report and associated images.

\section{CASE}

A 35-year-old female, 10-days post-partum, presented to an outside facility with acute onset, severe, substernal chest pain with radiation to back and left upper arm. She went into cardiorespiratory arrest upon arrival to the emergency room where she was successfully resuscitated from ventricular fibrillation with return of spontaneous circulation following prompt defibrillation. A 12-lead electrocardiogram revealed tombstone ST elevation in anterior leads (Fig. 1). She was transferred to our institution through the Level 1 Acute Myocardial Infarction (AMI) Program [1]. Coronary angiography revealed a dissection flap in the proximal left anterior descending (LAD) coronary artery, extending to the mid-LAD (Fig. 2), consistent with SCAD. PCI was performed with placement of three drugeluting stents (Fig. 3). Initial 2-dimensional echocardiogram revealed a left ventricular ejection fraction (LVEF) of 25\%. Systemic hypotension was treated with vasopressors and mechanical circulatory support with intraaortic balloon counterpulsation. Creatine kinase-MB fraction peaked at $631 \mathrm{IU} / \mathrm{mL}$. Cardiac magnetic resonance imaging at day 10 showed a transmural infarction involving inferoseptal, apical anterior, and lateral walls with significant microvascular obstruction. LVEF was calculated at $41 \%$.

The patient was referred to the Cardiovascular Cell Therapy Research Network LateTIME trial (Clinicaltrials.gov \# NCT00684060) [2], which required repeat coronary angiography that revealed the presence of thrombus throughout the LAD (Fig. 4) requiring aspiration thrombectomy and administration of a glycoprotein IIb-IIIa antagonist. IVUS showed that the previously deployed stents were in the false lumen with spontaneous re-canalization of the true lumen (Fig. 5). Sequential balloon angioplasty was done with expansion of stents into the true lumen followed by PCI of distal LAD (Fig. 6). At 2-year follow-up, the patient has done well, including a subsequent pregnancy delivered by cesarean section. Her most recent LVEF was $40-45 \%$.

\section{DISCUSSION}

SCAD is a rare, life-threatening condition that usually manifests as an AMI. The prevalence of SCAD has been reported at $0.1-1.0 \%$ [3]. Although prior literature states that it predominantly affects women with no cardiovascular risk factors, a recently published prospective series from Spain has suggested that patients with isolated-SCAD often also have concomitant cardiovascular risk factors [4]. SCAD associated with coronary artery disease, however, is more common in men [4]. A retrospective review reports that $26 \%$ of SCAD is associated with pregnancy, of which $83.8 \%$ cases occur in the postpartum period between the third trimester and 4-month postpartum [5].

Diagnosing SCAD with conventional coronary angiogram can be challenging, particularly if the true lumen is severely narrowed. The classic description is that of contrast media visualized in two lumens separated by a radiolucent intimal flap, with persistence of contrast in the false lumen. Alternatively, hematoma filling the false 


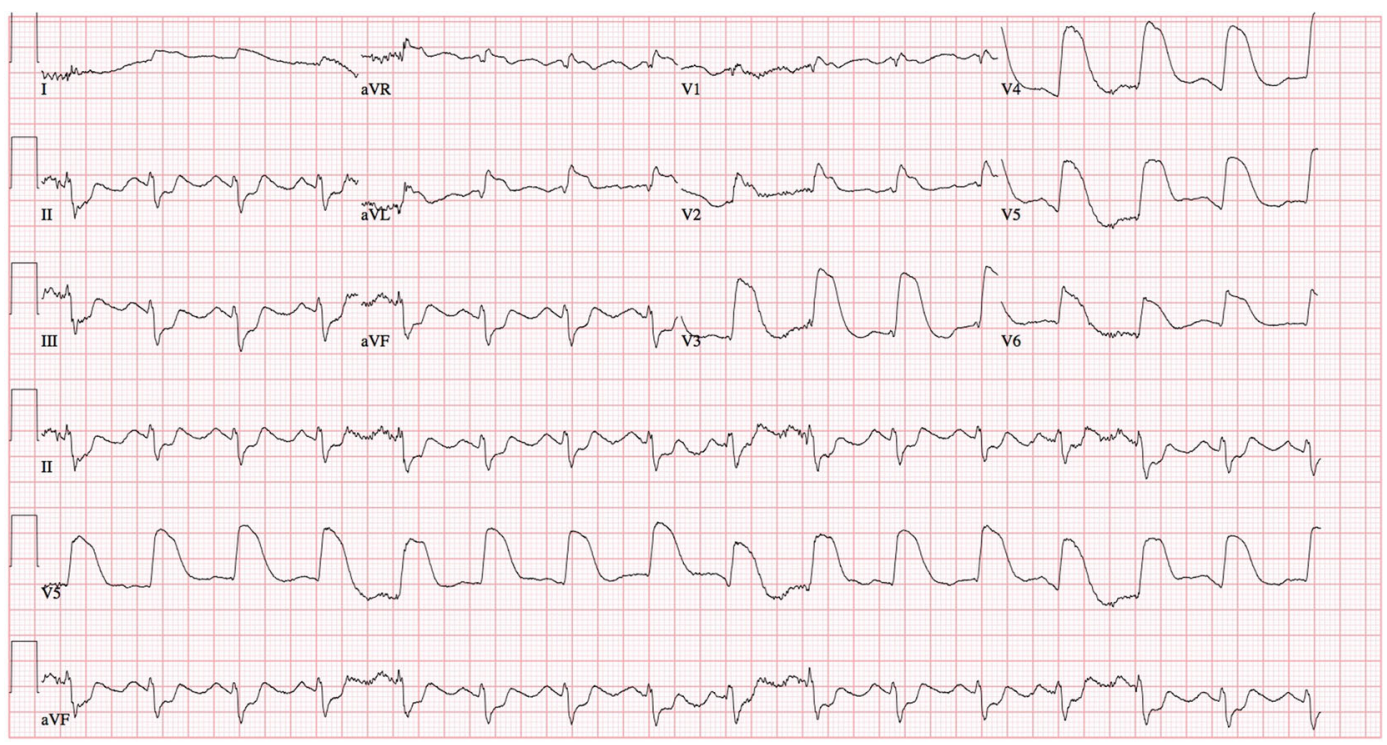

Fig. 1 12-Lead electrocardiogram showing tombstone ST elevation current of injury in anterior leads

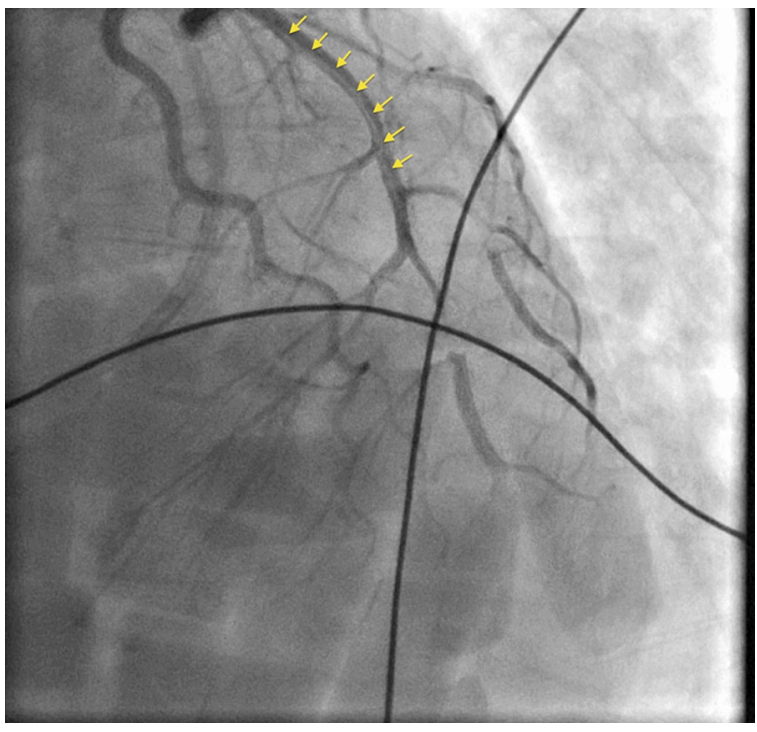

Fig. 2 Coronary angiogram showing dissection flap extending from proximal to mid-left anterior descending coronary artery (yellow arrows)

lumen may simulate an intracoronary thrombus. Also, inability to visualize complete coronary wall makes differentiation of true versus false lumen difficult, thereby limiting the diagnostic accuracy of coronary angiography [6]. IVUS, however, is able to identify the three-layered intima-medial flap

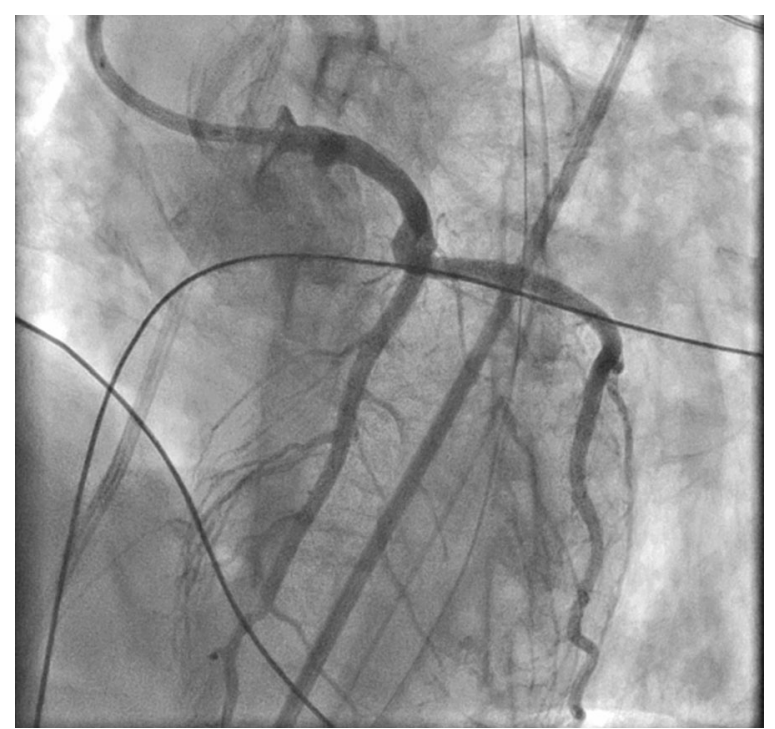

Fig. 3 Coronary angiogram following percutaneous coronary intervention with placement of 3 drug-eluting stents in the left anterior descending coronary artery

overlying the darker, thrombosed false lumen with complete visualization of the external elastic lamina [7].

Because of lack of randomized trial data, the treatment of SCAD in the setting of ST segment elevation myocardial infarction has not been standardized. Much of the literature supporting 


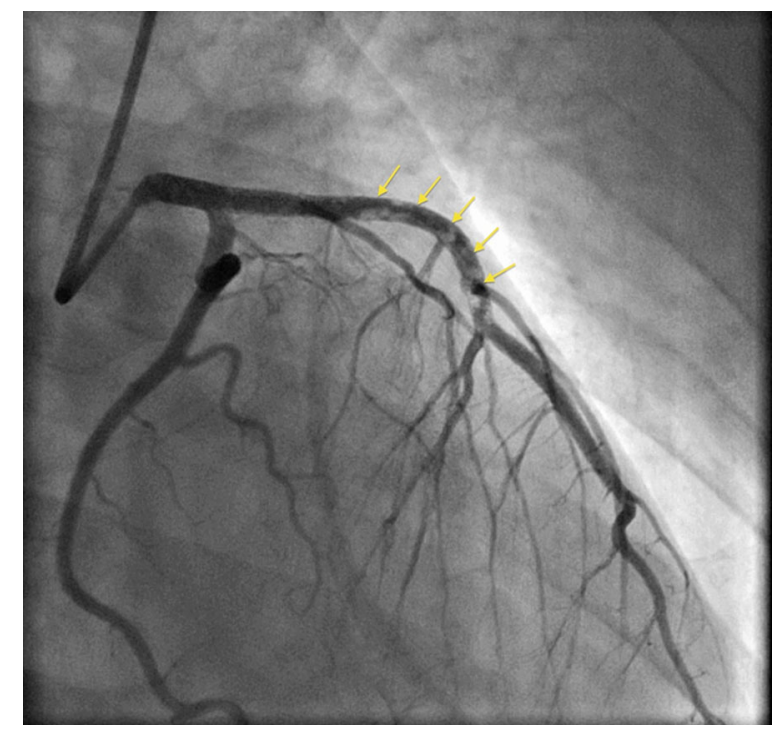

Fig. 4 Coronary angiogram on day 14 showing thrombotic occlusion of the left anterior descending coronary artery (yellow arrows)

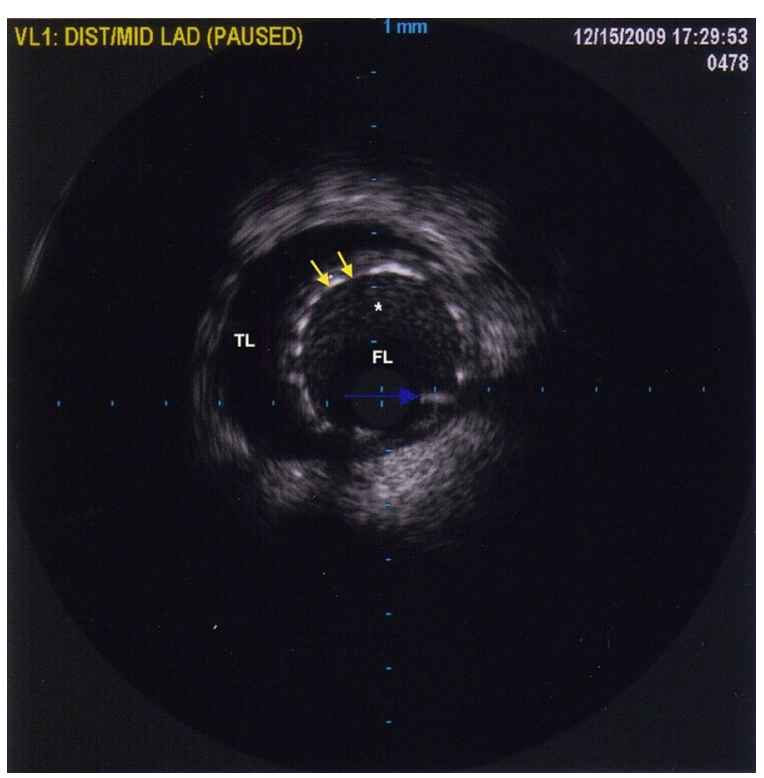

Fig. 5 Intravascular ultrasound showing placement of stents (yellow arrows showing stent struts) in the false lumen (FL) with spontaneous re-canalization of the true lumen [TL dye contrast (black)]. There is thrombus (gray; asterisk) in the $\mathrm{FL}$

current practice of PCI is derived from cases that were managed as acute coronary syndromes due to plaque rupture or erosion. Retrospective data

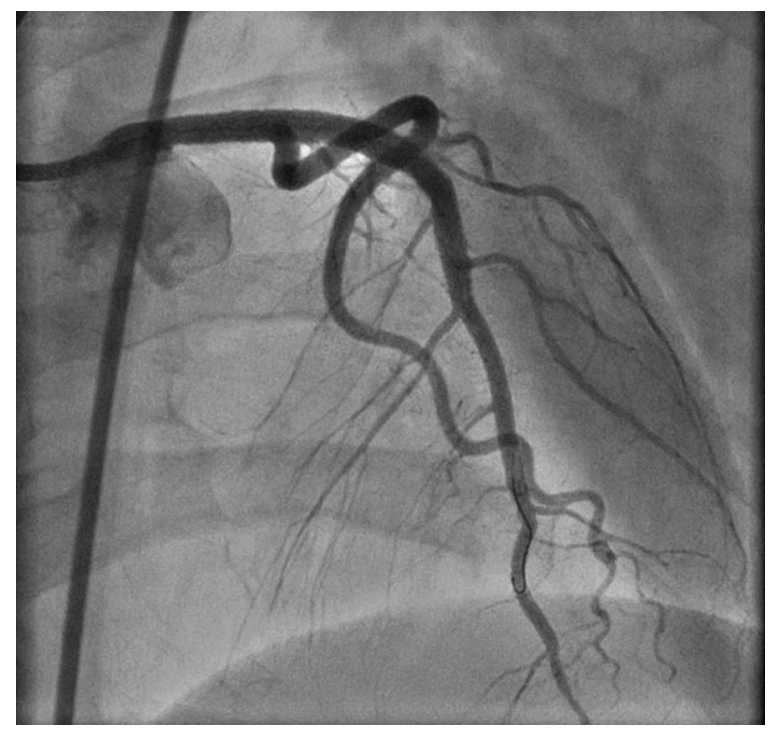

Fig. 6 Coronary angiogram following sequential balloon angioplasty and percutaneous coronary intervention of distal left anterior descending coronary artery

have favored early invasive approach with PCI in SCAD cases that involve major epicardial coronary vessels with representative changes on a surface electrocardiogram $[5,8]$. However, the recent prospective study from Spain has demonstrated that many patients who were managed "conservatively" at presentation demonstrated spontaneous healing and recanalization at follow-up [4]. In this study, selective revascularization of the affected vessel with PCI was only performed in patients with on-going ischemia, as also demonstrated in our case. The initial treatment strategy in stable, symptom-free patients was "watchful waiting" that resulted in excellent long-term prognosis, as demonstrated in SCAD cases presenting as AMI with single-vessel dissection, preserved blood flow [9], and hemodynamic stability [10].

Our case also highlights the challenges in performing successful PCI in patients with SCAD. IVUS can prove to be a pivotal tool in the diagnosis and successful management of such cases [11] by establishing the anatomic site 
of dissection and confirming stent placement in the true lumen following PCI. Apposition of stents to the false luminal wall can result in complete collapse of the true lumen leading to catastrophic outcomes [12]. Our patient had spontaneous re-canalization of the true lumen with stents in the false lumen that was successfully managed with sequential balloon angioplasty. In retrospect, application of IVUS imaging for ascertainment of proper positioning of guidewire in the true lumen during PCI at index presentation may have prevented stent placement in the false lumen [13].

\section{CONCLUSION}

PCI is indicated in patients with SCAD with ongoing or recurrent ischemia. Satisfactory stent deposition can be challenging in SCAD and additional tomographic techniques are required to delineate the double-lumen morphology and proper positioning of guidewire in the true lumen. IVUS can play a significant role in ensuring procedural success. With appropriate revascularization, patients have excellent long-term prognosis with this rare, life-threatening disease [4].

\section{ACKNOWLEDGMENTS}

No funding or sponsorship was received for this study or publication of this article. All named authors meet the ICMJE criteria for authorship for this manuscript, take responsibility for the integrity of the work as a whole, and have given final approval for the version to be published.

Conflict of interest. Ankur Kalra, Avin Aggarwal, Rachel Kneeland, and Jay $\mathrm{H}$. Traverse declare no conflict of interest.
Compliance with ethics guidelines. Informed consent was obtained from the patient for publication of this case report and associated images.

Open Access. This article is distributed under the terms of the Creative Commons Attribution Noncommercial License which permits any noncommercial use, distribution, and reproduction in any medium, provided the original author(s) and the source are credited.

\section{REFERENCES}

1. Henry TD, Sharkey SW, Burke MN, et al. A regional system to provide timely access to percutaneous coronary intervention for ST-elevation myocardial infarction. Circulation. 2007;116(7):721-8.

2. Traverse JH, Henry TD, Ellis SG, et al. Effect of intracoronary delivery of autologous bone marrow mononuclear cells 2 to 3 weeks following acute myocardial infarction on left ventricular function: the LateTIME randomized trial. JAMA. 2011;306(19):2110-9.

3. Motreff P, Souteyrand G, Dauphin C, Eschalier R, Cassagnes J, Lusson JR. Management of spontaneous coronary artery dissection: review of the literature and discussion based on a series of 12 young women with acute coronary syndrome. Cardiology. 2010;115:10-8.

4. Alfonso F, Paulo M, Lennie V, et al. Spontaneous coronary artery dissection: long-term follow-up of a large series of patients prospectively managed with a "conservative" therapeutic strategy. JACC Cardiovasc Interv. 2012;5(10):1062-70.

5. Shamloo BK, Chintala RS, Nasur A, et al. Spontaneous coronary artery dissection: aggressive vs. conservative therapy. J Invasive Cardiol. 2010;22(5):222-8.

6. Alfonso F, Paulo M, Gonzalo N, et al. Diagnosis of spontaneous coronary artery dissection by optical coherence tomography. J Am Coll Cardiol. 2012;59(12):1073-9.

7. Paulo M, Sandoval J, Lennie V, et al. Combined use of OCT and IVUS in spontaneous coronary artery dissection. JACC Cardiovasc Imaging. 2013;6(7):830-2. 
8. Adlam D, Cuculi F, Lim C, Banning A. Management of spontaneous coronary artery dissection in the primary percutaneous coronary intervention era. J Invasive Cardiol. 2010;22(11):549-53.

9. Maeder M, Ammann P, Angehrn W, Rickli H. Idiopathic spontaneous coronary artery dissection: incidence, diagnosis and treatment. Int J Cardiol. 2005;101(3):363-9.

10. Celik M, Yuksel UC, Yalcinkaya E, Gokoglan Y, Iyisoy A. Conservative treatment of iatrogenic left main coronary artery dissection: report of two cases. Cardiovasc Diagn Ther. 2013;3(4):244-6.
11. Daoulah A, Al Qahtani A, Mazen Malak $M, A l$ Ghamdi S. Role of IVUS in assessing spontaneous coronary dissection: a case report. J Tehran Heart Cent. 2012;7(2):78-81.

12. Suarez-Mier MP, Merino JL. False lumen stent placement during iatrogenic coronary dissection. Cardiovasc Pathol. 2013;22(2):176-7.

13. Ohlmann P, Weigold G, Kim SW, et al. Images in cardiovascular medicine. Spontaneous coronary dissection: computed tomography appearance and insights from intravascular ultrasound examination. Circulation. 2006;113(10):e403-5. 